American Journal of Infectious Diseases 3 (1): 42-50, 2007

ISSN 1553-6203

(C) 2007 Science Publications

\title{
Evaluation of Acute-phase Reactants, Immunologic Markers and other Clinical and Laboratory Parameters in Patients with Pneumonia and Non-pneumonic Lower Respiratory Tract Infections
}

\author{
${ }^{1}$ Julio Collazos, ${ }^{2}$ María del Mar Martínez and ${ }^{3}$ Fernando Izquierdo \\ ${ }^{1}$ Section of Infectious Diseases, ${ }^{2}$ Section of Emergency Medicine \\ ${ }^{3}$ Service of Biochemistry, Hospital de Galdácano-Usánsolo, Vizcaya, Spain
}

\begin{abstract}
More efficacious tools to distinguish pneumonia from other acute lower respiratory tract infections (OALRTI) in facilities where radiologic studies are not easily or rapidly available are desirable to select the patients who should undergo chest radiographs, to avoid unnecessary visits to the emergency wards of hospitals and to optimize health resources. To this end we analyzed the relevance of many clinical and laboratory parameters, including acute-phase reactants and immune activation markers, in 98 patients with pneumonia and 149 with OALRTI seen at the emergency ward of our hospital. Many clinical and laboratory parameters were associated with the diagnosis of pneumonia in the univariate analysis. Among them, C-reactive protein proved to be the most discriminant for the differentiation between the two conditions (area under the ROC curve 0.83, 95\%CI 0.78-0.89, $\mathrm{P}<0.0001)$. A multivariate logistic regression analysis revealed that $\mathrm{C}$-reactive protein, presence of suggestive auscultatory findings, lower age, presence of pleuritic pain and lower percent of eosinophils were independently associated with the diagnosis of pneumonia. A formula was derived from this analysis, which, for the most discriminant cut-off level, correctly classified pneumonic and non-pneumonic patients with a sensitivity of $88 \%$ and specificity $90 \%$. The area under the ROC curve of this predictive model was 0.93 (95\% CI 0.89-0.96, $\mathrm{P}<0.0001)$. C-reactive protein, especially if combined with other easily obtained parameters, constitutes a useful adjunct for the differentiation of pneumonia from OALRTI. Routine measurement of these parameters could result in a more adequate utilization of resources.
\end{abstract}

Key words: Acute-phase reactants, C-reactive protein, pneumonia, respiratory tract infections

\section{INTRODUCTION}

Many patients with community-acquired lower respiratory tract infections are unnecessarily seen in the emergency wards of hospitals, mainly in the winter months, which generate overload, increased health expenditures and inconveniences for the patients. This problem is even higher in countries such as ours in which emergency ward consultations, diagnostic tests and treatments are provided free of charge for all patients, which results in that many patients go to the emergency ward by their own instead of being previously evaluated by a general practitioner.

Unfortunately, no single symptom or physical finding has proved to have enough predictive value for the diagnosis of pneumonia ${ }^{[1-5]}$. New chest signs on examination, even if focal and suggestive, are helpful but not specific ${ }^{[3-5]}$. Therefore, additional, reliable, costeffective and easily obtained diagnostic tools are highly desirable.
C-reactive protein (CRP), an acute-phase reactant primarily synthesized by hepatocytes as a response mainly to interleukin-6, markedly increases with acute invasive infections paralleling the severity of inflammation or tissue injury ${ }^{[5]}$. CRP has also been identified in respiratory secretions, where it may contribute to bacterial clearance $e^{[7,8]}$ and its determination has been considered useful for the diagnosis and management of pneumonia ${ }^{[1,3,9,10]}$. Erythrocyte sedimentation rate (ESR) is another widely available acute-phase reactant that has also been occasionally evaluated in patients with lower respiratory tract infections ${ }^{[1,9,11]}$.

Adenosine deaminase (ADA), an enzyme responsible for the conversion of adenosine and deoxyadenosine to inosine and deoxyinosine, is involved in the proliferation and differentiation of lymphocytes and monocytes ${ }^{[12,13]}$. Although serum ADA has been evaluated mainly in patients with tuberculosis ${ }^{[12-16]}$, it has also been analyzed in a few 
reports of non-tuberculous lower respiratory tract infections $^{[17-21]}$.

$\beta_{2}$-microglobulin $(\beta 2-\mathrm{M})$, a membrane protein of low molecular weight, is a component of the class 1 major histocompatibility complex. $\beta_{2}-\mathrm{M}$ is found on most nucleated cells, including lymphoid and monocytoid cells. Immune activation and increased turnover of these cells, particularly T-lymphocytes, result in an increased release of $\beta_{2}-\mathrm{M}$ into the circulation. Increased levels of this protein have been found in a variety of infectious, inflammatory and neoplastic conditions ${ }^{[22-26]}$ and it has been marginally evaluated in some studies dealing with a reduced number of patients with lower respiratory tract infections $^{[26-28]}$.

The aim of this prospective study was analyze the behavior of these acute-phase reactants and immune activation markers, as well as many other basic clinical and laboratory parameters, in patients with pneumonia and other acute lower respiratory tract infections (OALRTI) at the time of presentation to the emergency ward of our hospital. From this information we also try to derive rules and to define the usefulness of these parameters for the differential diagnosis of both infections, which could help to a better classification of patients and therefore, to prevent unnecessary radiographic studies, sparing costs and optimizing emergency ward resources.

\section{MATERIALS AND METHODS}

The study group was composed of 247 unselected patients, 144 men and 103 women, with lower respiratory tract infections seen at the emergency ward of our hospital. Patients with tuberculosis and patients with HIV-infection had been excluded from the study. All patients underwent a thorough evaluation that included many clinical and laboratory parameters. The patients' final diagnosis (pneumonia or OALRTI) and the number of in-patient days in those patients who were admitted were also recorded. All blood samples were obtained simultaneously at the time of clinical evaluation in the emergency ward, but the results of CRP, ESR, ADA and $\beta 2-M$ were unknown to the clinicians involved in the patients' care and the clinical features and diagnosis of the patients were also unknown to those that performed the laboratory determinations.

As the aim of this study was the evaluation of patients with lower respiratory tract infections in routine clinical practice, the clinicians involved in their care were not specifically instructed on how to evaluate the patients and did not follow any study protocol. This was an essential point in our study, as our objective was to extrapolate our findings to the general population and to routine clinical practice, minimizing the double observational bias (both from patients' and doctors' perspectives) inherent to investigational studies. Although radiologic findings were recorded for diagnostic purposes, they have not been analyzed in this study because imaging procedures are not easily and quickly available to general practitioners in the evaluation of respiratory infections outside the hospital and because we intended to develop prediction rules in the absence of chest radiographs.

Pneumonia was defined as symptoms and signs consistent with an acute lower respiratory tract infection associated with new radiographic shadowing for which there is no other explanation ${ }^{[29]}$. CRP was measured by immunoturbidimetry in an automatic autoanalyzer HITACHI 747 using a commercial kit (Roche Diagnostics Systems). ESR was determined in a platform SediSystem (Becton Dickinson) based in the system seditainer ${ }^{\mathrm{TM}}$, which is a variant of the standard technique of Westergreen. ADA was measured by a commercial, enzymatic ultraviolet test that uses NADH as substrate (Roche Diagnostics Systems). $\beta_{2}-\mathrm{M}$ was determined by a Microparticle Enzyme Immunoassay test in a platform AxSYM ${ }^{\mathrm{TM}}$ using a commercial kit (Abbott Laboratories, Illinois, USA). The upper normal limits were $5 \mathrm{mg} \mathrm{L}^{-1}$ for CRP, $20 \mathrm{~mm}$ at the first hour for ESR, 18.2 $\mathrm{U} \mathrm{L}^{-1}$ for ADA and $2.4 \mathrm{mg} \mathrm{L}^{-1}$ for $\beta_{2}-\mathrm{M}$.

Statistical analysis: Neither CPR, ESR, $\beta 2-\mathrm{M}$ or ADA followed a gaussian distribution. Consequently, nonparametric tests were used for statistical analysis. The correlation between two continuous variables was assessed by the Spearman's correlation coefficient. The Mann-Whitney $\mathrm{U}$ test was used for the comparison of two groups and the Kruskal-Wallis test for the evaluation of more than two groups. Categorical variables were compared with the chi-square test. Sensitivities, specificities, predictive values, likelihood ratios and odds ratios for the diagnosis of pneumonia were calculated from $2 \times 2$ tables. Receiver-operating characteristics (ROC) curves, as well as the area under the curve, were calculated for each continuous variable to assess their diagnostic performance for the detection of pneumonia at different cut-off levels. A stepwise multiple regression analysis was used to detect the variables independently associated with CRP, ESR, ADA and $\beta 2-\mathrm{M}$. The identification of the parameters predictive of the diagnosis of pneumonia after adjustment for other variables was carried out with a multiple logistic regression analysis. A P value $<0.05$ for a two-sided test was considered statistically 
significant. SPSS v. 13.0 was used for the statistical analysis.

\section{RESULTS}

The patients' mean age was 58.5 years $(95 \%$ CI 55.8 to 61.2 years). Ninety-eight patients $(39.7 \%)$ had a final diagnosis of pneumonia, whereas the remaining 149 patients $(60.3 \%)$ were diagnosed with OALRTI. Values above the upper normal limit of CRP for pneumonic and non-pneumonic patients were observed in $98.9 \%$ and $94.1 \%$, of ESR in 81.1 and $49.6 \%$, of ADA in 50 and $68.1 \%$ and of $\beta 2-\mathrm{M}$ in 28.9 and $36.1 \%$, respectively. The associations of CRP, ESR, ADA and $\beta 2-\mathrm{M}$ with diverse demographic, clinical and laboratory parameters are shown in Table 1. CRP correlated with the number of days spent in the hospital in patients with pneumonia $(\mathrm{r}=0.28, \mathrm{P}=0.04)$ and in those with OALRTI $(\mathrm{r}=0.34, \mathrm{P}=0.003)$, whereas ESR showed a significant correlation with that parameter only in non-pneumonic patients $(\mathrm{r}=0.39, \mathrm{P}=0.001)$. CRP, but not $\mathrm{ESR}$, was significantly associated with the destination of the patient after the initial evaluation at the emergency ward (admitted vs. discharged home) in patients with pneumonia (median 200.5 vs. $117 \mathrm{mg} \mathrm{L}^{-1}$, respectively, $\mathrm{P}=0.002$ ) and in patients with OALRTI (median 62 vs. $18.1 \mathrm{mg} \mathrm{L}^{-1}$, respectively, $\mathrm{P}<0.0001$ ). The parameters statistically significant in the univariate analysis were entered into a multivariate model. The parameters independently associated with each of the acute-phase and immunological markers are shown in Table 2.

Figure 1 depicts the median values of CRP, ESR, $\beta 2-\mathrm{M}$ and ADA in patients with pneumonia and OALRTI. As it can be seen, despite the significant differences between both conditions, there was considerable overlapping for all markers except for CRP. ROC curves were elaborated for each continuous variable, including the four acute-phase or immunological markers. The two more discriminant variables for the diagnosis of pneumonia were those of CRP and ESR. Figure 2 shows the curves of CRP, ESR, ADA and $\beta 2-\mathrm{M}$ only. The area under the ROC curve for CRP was 0.83 (95\% CI $0.78-0.89, \mathrm{P}<0.0001$ ), for ESR 0.74 (95\% CI 0.67-0.81, $\mathrm{P}<0.0001)$, for ADA 0.38 (95\% CI 0.30-0.45, $\mathrm{P}=0.002)$ and for $\beta 2-\mathrm{M} 0.43(95 \%$ CI $0.36-0.51, \mathrm{P}=0.09)$. The most discriminant value of all variables corresponded to CRP and was $71 \mathrm{mg} \mathrm{L}^{-1}$ (sensitivity $77.5 \%$, specificity $76.5 \%$, positive predictive value $68.3 \%$, negative predictive value 83.9, likelihood ratio+ 3.3 (95\% CI 2.4-4.5), likelihood ratio0.29 (95\% CI 0.26-0.44), odds ratio 11.2 (95\% CI 6.220.3).

Table 3 shows the associations of the diverse demographic, clinical and laboratory parameters with the diagnosis of pneumonia and OALRTI.

Table 1: Association of acute-phase reactants and immune activation markers with demographic, clinical and laboratory parameters

\begin{tabular}{|c|c|c|c|c|c|c|c|c|c|}
\hline \multirow[b]{2}{*}{ Continuous variables } & \multirow[b]{2}{*}{ Units } & \multicolumn{2}{|l|}{ CRP } & \multicolumn{2}{|l|}{ ESR } & \multicolumn{2}{|c|}{$\mathrm{ADA}$} & \multicolumn{2}{|l|}{$\beta 2-\mathrm{M}$} \\
\hline & & $\mathrm{r}$ & $\mathrm{P}$ & $\mathrm{r}$ & $\mathrm{P}$ & $\mathrm{r}$ & $\mathrm{P}$ & $\mathrm{r}$ & $\mathrm{P}$ \\
\hline Age & years & -0.05 & 0.49 & 0.10 & 0.13 & 0.02 & 0.77 & 0.42 & $<0.0001$ \\
\hline Duration of symptoms & days & -0.16 & 0.02 & 0.12 & 0.08 & -0.01 & 0.87 & -0.09 & 0.16 \\
\hline Maximum temperature at home & ${ }^{\circ} \mathrm{C}$ & 0.34 & $<0.0001$ & 0.16 & 0.02 & 0.001 & 0.99 & 0.05 & 0.41 \\
\hline Temperature on arrival at hospital & ${ }^{\circ} \mathrm{C}$ & 0.33 & $<0.0001$ & 0.11 & 0.11 & -0.04 & 0.51 & 0.03 & 0.67 \\
\hline Leukocytes & counts $\mu \mathrm{L}^{-1}$ & 0.39 & $<0.0001$ & 0.27 & $<0.0001$ & -0.46 & $<0.0001$ & -0.23 & 0.0004 \\
\hline Polymorphonuclear cells & $\%$ & 0.26 & $<0.0001$ & 0.10 & 0.15 & -0.24 & 0.0002 & 0.004 & 0.95 \\
\hline Band forms & $\%$ & 0.44 & $<0.0001$ & 0.21 & 0.002 & -0.11 & 0.10 & 0.07 & 0.31 \\
\hline Lymphocytes & $\%$ & -0.39 & $<0.0001$ & -0.14 & 0.03 & 0.20 & 0.003 & -0.11 & 0.10 \\
\hline Monocytes & $\%$ & -0.16 & 0.02 & -0.07 & 0.27 & 0.34 & $<0.0001$ & 0.14 & 0.03 \\
\hline Eosinophils & $\%$ & -0.37 & $<0.0001$ & -0.12 & 0.07 & 0.01 & 0.9 & -0.08 & 0.2 \\
\hline Hemoglobin & $\mathrm{g} \mathrm{dL}^{-1}$ & -0.18 & 0.006 & -0.48 & $<0.0001$ & 0.14 & 0.03 & -0.08 & 0.2 \\
\hline Platelets & counts $\mu \mathrm{L}^{-1}$ & 0.00 & 0.99 & 0.27 & $<0.0001$ & -0.32 & $<0.0001$ & -0.40 & $<0.0001$ \\
\hline Urea & $\mathrm{mg} \mathrm{dL}^{-1}$ & 0.10 & 0.14 & 0.01 & 0.87 & -0.12 & 0.06 & 0.40 & $<0.0001$ \\
\hline Creatinine & $\mathrm{mg} \mathrm{dL}^{-1}$ & 0.09 & 0.18 & -0.09 & 0.18 & 0.07 & 0.31 & 0.44 & $<0.0001$ \\
\hline Alanine aminotransferase & $\mathrm{U} / \mathrm{L}^{-1}$ & 0.01 & 0.89 & -0.04 & 0.53 & 0.25 & 0.0001 & 0.04 & 0.56 \\
\hline Blood $\mathrm{pH}$ & & 0.21 & 0.002 & 0.19 & 0.004 & -0.11 & 0.11 & -0.08 & 0.22 \\
\hline Blood pCO2 & $\mathrm{mm} \mathrm{Hg}$ & -0.13 & 0.06 & -0.08 & 0.26 & 0.09 & 0.18 & 0.09 & 0.15 \\
\hline Blood pO2 & $\mathrm{mm} \mathrm{Hg}$ & -0.19 & 0.005 & -0.16 & 0.02 & 0.01 & 0.85 & -0.23 & 0.0005 \\
\hline Blood bicarbonate & $\mathrm{mEq} \mathrm{L}^{-1}$ & -0.02 & 0.72 & 0.00 & 0.96 & 0.09 & 0.16 & 0.12 & 0.07 \\
\hline Saturation of $\mathrm{O} 2$ & $\%$ & -0.12 & 0.08 & -0.10 & 0.15 & -0.02 & 0.73 & -0.27 & $<0.0001$ \\
\hline $\begin{array}{l}\text { Duration of admission to hospital } \\
\text { (only for admitted patients) }\end{array}$ & days & 0.36 & $<0.0001$ & 0.36 & $<0.0001$ & -0.03 & 0.66 & 0.18 & 0.005 \\
\hline C-reactive protein & $\mathrm{mg} \mathrm{L}^{-1}$ & - & - & 0.58 & $<0.0001$ & -0.23 & 0.0007 & 0.08 & 0.23 \\
\hline Erythrocyte sedimentation rate & $\mathrm{mm} \mathrm{h}^{-1}$ & 0.58 & $<0.0001$ & - & - & -0.13 & 0.07 & 0.08 & 0.23 \\
\hline Adenosine deaminase & $\mathrm{UL}^{-1}$ & -0.23 & 0.0007 & -0.01 & 0.07 & - & - & 0.39 & $<0.0001$ \\
\hline$\beta 2$-microglobulin & $\mathrm{mg} \mathrm{L}^{-1}$ & 0.08 & 0.22 & 0.08 & 0.23 & 0.39 & $<0.0001$ & - & - \\
\hline
\end{tabular}


Am. J. Infect. Dis., 3 (1): 42-50, 2007

Table 1. Cont.

\begin{tabular}{|c|c|c|c|c|c|c|c|c|c|}
\hline Categorical variables & Options & median & $\mathrm{P}$ & median & $\mathrm{P}$ & median & $\mathrm{P}$ & median & $\mathrm{P}$ \\
\hline \multirow{2}{*}{ Gender } & Male & 70.3 & 0.03 & 28 & 0.1 & 19.8 & 0.4 & 2.1 & 0.3 \\
\hline & Female & 37.3 & & 32 & & 21.1 & & 1.91 & \\
\hline \multirow{4}{*}{$\begin{array}{l}\text { Reason for attending } \\
\text { the hospital } \\
\text { Concomitant conditions }\end{array}$} & Medical referral & 65.7 & 0.6 & 37 & 0.001 & 20.2 & 0.8 & 2.04 & 0.5 \\
\hline & Patient's decision & 60.5 & & 26 & & 20.1 & & 2 & \\
\hline & Yes & 56 & 0.7 & 31 & 0.9 & 20.8 & 0.4 & 2.2 & 0.0006 \\
\hline & No & 66.3 & & 26.5 & & 18.9 & & 1.81 & \\
\hline \multirow[t]{3}{*}{ Type of condition } & COPD & 54.1 & 0.6 & 24.5 & 0.5 & 19.4 & 0.7 & 2.28 & 0.001 \\
\hline & Others & 62 & & 32 & & 21.5 & & 2.04 & \\
\hline & None & 66.3 & & 26.5 & & 18.9 & & 1.81 & \\
\hline \multirow[t]{3}{*}{ Prior steroid treatment } & Yes, oral & 34 & 0.002 & 16 & 0.0008 & 19.8 & 0.8 & 1.85 & 0.6 \\
\hline & Yes, inhaled & 18.6 & & 14.5 & & 19.4 & & 1.89 & \\
\hline & No & 70.2 & & 35 & & 20.6 & & 2.06 & \\
\hline Antibiotic treatment & Yes & 60.5 & 0.2 & 28 & 0.6 & 21.4 & 0.04 & 1.91 & 0.1 \\
\hline at the time of evaluation & No & 65.9 & & 31.5 & & 19.8 & & 2.2 & \\
\hline \multirow{2}{*}{ Cough } & Yes & 61 & 0.6 & 31 & 0.5 & 20.5 & 0.2 & 2.03 & 0.6 \\
\hline & No & 113.5 & & 15 & & 15.9 & & 1.6 & \\
\hline \multirow{2}{*}{ Sputum production } & Yes & 56 & 0.5 & 31 & 0.9 & 21.3 & 0.1 & 2.1 & 0.5 \\
\hline & No & 66.1 & & 32 & & 17.2 & & 1.9 & \\
\hline \multirow[t]{2}{*}{ Purulent sputum } & Yes & 54.6 & 0.6 & 33 & 0.6 & 19.8 & 0.4 & 1.89 & 0.01 \\
\hline & No & 67.4 & & 28 & & 20.9 & & 2.14 & \\
\hline \multirow[t]{2}{*}{ Dyspnea at home } & Yes & 53 & 0.1 & 31 & 0.8 & 20.6 & 0.5 & 2.26 & 0.01 \\
\hline & No & 71.8 & & 31 & & 18.9 & & 1.82 & \\
\hline Dyspnea at the time & Yes & 64 & 0.9 & 26 & 0.1 & 20.4 & 0.3 & 2.225 & 0.01 \\
\hline of evaluation & No & 58.5 & & 33 & & 20 & & 1.915 & \\
\hline \multirow[t]{2}{*}{ Pleuritic chest pain } & Yes & 124.7 & $<0.0001$ & 43 & 0.048 & 15.75 & $<0.0001$ & 1.775 & 0.01 \\
\hline & No & 44.3 & & 27 & & 21.75 & & 2.165 & \\
\hline & Yes & 172.5 & $<0.0001$ & 47 & $<0.0001$ & 18.2 & 0.007 & 1.915 & 0.4 \\
\hline findings & No & 37 & & 25.5 & & 21.7 & & 2.04 & \\
\hline \multirow[t]{2}{*}{ Pathogen } & Pneumococci & & 0.006 & 55 & 0.3 & 20.45 & 0.6 & 1.68 & 0.3 \\
\hline & Others/unknown & 58.3 & & 31 & & 20.2 & & 2.04 & \\
\hline Destination & Hospitalized & & $<0.0001$ & 35.5 & 0.003 & 19.9 & 0.9 & 2.32 & 0.0006 \\
\hline after evaluation & Discharged home & 34.6 & & 24 & & 21.1 & & 1.815 & \\
\hline
\end{tabular}

CRP denotes C-reactive protein, ESR erythrocyte sedimentation rate, ADA adenosine deaminase and $\beta 2$-M $\beta 2$-microglobulin

Table 2: Multivariate analyses for each acute-phase reactant and immune activation marker

\begin{tabular}{|c|c|c|c|}
\hline Outcome variable & Explanatory parameter & $\mathrm{P}$ value & $\begin{array}{l}\% \text { of the outcome variable } \\
\text { accounted for the model }\end{array}$ \\
\hline \multirow[t]{5}{*}{ C-reactive protein } & Erythrocyte sedimentation rate & $<0.0001$ & $64.7 \%$ \\
\hline & Final diagnosis of pneumonia & $<0.0001$ & \\
\hline & Percent of band forms & $<0.0001$ & \\
\hline & Leukocyte count & 0.002 & \\
\hline & Number of in-patient days & 0.002 & \\
\hline \multirow[t]{5}{*}{ Erythrocyte sedimentation rate } & C-reactive protein & $<0.0001$ & $61.1 \%$ \\
\hline & Lower hemoglobin values & $<0.0001$ & \\
\hline & Higher platelet count & $<0.0001$ & \\
\hline & Lower leukocyte count & 0.002 & \\
\hline & Sent to hospital because of medical decision & 0.01 & \\
\hline \multirow[t]{5}{*}{ Adenosine deaminase } & Lower leukocyte count & 0.001 & $23.4 \%$ \\
\hline & Lower platelet count & 0.002 & \\
\hline & $\beta 2$-microglobulin & 0.005 & \\
\hline & Alanine aminotransferase & 0.009 & \\
\hline & Prior antibiotic treatment & 0.03 & \\
\hline \multirow[t]{6}{*}{$\beta 2$-microglobulin } & Creatinine & $<0.0001$ & $65.9 \%$ \\
\hline & Age & $<0.0001$ & \\
\hline & Adenosine deaminase & 0.0002 & \\
\hline & Lower leukocyte count & 0.003 & \\
\hline & Non-purulent sputum & 0.01 & \\
\hline & Admission to hospital & 0.02 & \\
\hline
\end{tabular}

Table 4 reflects the variables independently associated with the diagnosis of pneumonia in a logistic regression analysis that included the variables statistically significant in the univariate analysis, a model that adequately fitted the data according to the HosmerLemeshow goodness-of-fit statistic.
A formula was derived from this analysis for the prediction of pneumonia in each individual case: $3.34+$ $(0.01 \times \mathrm{CRP})-(0.04 \times$ age $)-(0.58 \times$ percent of eosinophils) +1.78 [only if pleuritic pain present] + 2.66 [only if suggestive auscultatory findings present]. The most discriminant cut-off level of the formula was 
Am. J. Infect. Dis., 3 (1): 42-50, 2007

Table 3: Association of diverse parameters with the diagnosis of pneumonia or other acute lower respiratory tract infections (OALRTI)

\begin{tabular}{|c|c|c|c|}
\hline & Pneumonia & OALRTI & $\mathrm{P}$ value \\
\hline \multicolumn{4}{|l|}{ Categorical parameters } \\
\hline Male gender & $67.3 \%$ & $52.3 \%$ & 0.02 \\
\hline Sent to hospital by physician (vs. patient decision) & $51.0 \%$ & $43.0 \%$ & 0.2 \\
\hline Admitted (vs. discharged home) & $59.2 \%$ & $51.7 \%$ & 0.2 \\
\hline Prior underlying conditions & $59.2 \%$ & $73.2 \%$ & 0.02 \\
\hline COPD as underlying condition & $12.2 \%$ & $28.2 \%$ & 0.003 \\
\hline Non-COPD underlying condition & $46.9 \%$ & $45.0 \%$ & 0.8 \\
\hline Dyspnea reported by patient & $44.9 \%$ & $63.8 \%$ & 0.004 \\
\hline Dyspnea evaluated by the physician & $33.7 \%$ & $48.3 \%$ & 0.02 \\
\hline Pneumococcal etiology (vs. other/unknown) & $11.2 \%$ & $0 \%$ & $<0.0001$ \\
\hline Pleuritic pain & $51.0 \%$ & $18.1 \%$ & $<0.0001$ \\
\hline Suggestive auscultatory findings & $56.1 \%$ & $8.7 \%$ & $<0.0001$ \\
\hline Any steroid treatment & $9.2 \%$ & $21.5 \%$ & 0.01 \\
\hline Steroid treatment (oral) & $5.1 \%$ & $12.1 \%$ & 0.06 \\
\hline Steroid treatment (inhaled) & $4.3 \%$ & $10.4 \%$ & 0.1 \\
\hline Antibiotic treatment at the time of evaluation & $36.7 \%$ & $43.0 \%$ & 0.3 \\
\hline Cough & $95.9 \%$ & $96.0 \%$ & 1 \\
\hline Sputum production & $72.4 \%$ & $81.2 \%$ & 0.1 \\
\hline Purulent sputum & $54.1 \%$ & $60.0 \%$ & 0.3 \\
\hline \multicolumn{4}{|c|}{ Continuous parameters (values are expressed as the mean) } \\
\hline Age (years) & 52.7 & 62.3 & 0.0005 \\
\hline Number of days of symptoms & 6.4 & 9.0 & 0.2 \\
\hline Maximum temperature at home $\left({ }^{\circ} \mathrm{C}\right)$ & 38.5 & 37.7 & $<0.0001$ \\
\hline Temperature on arrival at hospital $\left({ }^{\circ} \mathrm{C}\right)$ & 37.8 & 37.0 & $<0.0001$ \\
\hline Leukocyte count $\mu \mathrm{L}^{-1}$ & 13450 & 9903 & $<0.0001$ \\
\hline Percent of polymorphonuclear cells & 75.3 & 72.0 & 0.04 \\
\hline Percent of band forms & 3.3 & 0.8 & $<0.0001$ \\
\hline Percent of eosinophils & 0.5 & 1.2 & $<0.0001$ \\
\hline Percent of lymphocytes & 13.3 & 16.9 & 0.001 \\
\hline Percent of monocytes & 7.4 & 8.5 & 0.01 \\
\hline Percent of basophils & 0.1 & 0.5 & 0.0002 \\
\hline Hemoglobin $\left(\mathrm{g} \mathrm{dL}^{-1}\right)$ & 13.8 & 14.2 & 0.03 \\
\hline Platelet count $\mu \mathrm{L}^{-1}$ & 240857 & 226473 & 0.4 \\
\hline Urea $\left(\mathrm{mg} \mathrm{dL}^{-1}\right)$ & 39.2 & 40.8 & 0.4 \\
\hline Creatinine $\left(\mathrm{mg} \mathrm{dL}^{-1}\right)$ & 1.1 & 1.0 & 0.5 \\
\hline Alanine aminotransferase $\left(\mathrm{U} \mathrm{L}^{-1}\right)$ & 37.4 & 26.3 & 0.3 \\
\hline Blood $\mathrm{pH}$ & 7.46 & 7.43 & $<0.0001$ \\
\hline Blood pCO2 (mm Hg) & 35.9 & 39.5 & $<0.0001$ \\
\hline Blood pO2 (mm Hg) & 75.2 & 74.9 & 0.5 \\
\hline Blood bicarbonate $\left(\mathrm{mEq} \mathrm{L}^{-1}\right)$ & 24.6 & 25.9 & 0.002 \\
\hline Saturation of O2 (\%) & 94.2 & 91.8 & 0.07 \\
\hline In-patient days (only for admitted patients) & 5.38 & 3.75 & 0.06 \\
\hline C-reactive protein $\left(\mathrm{mg} \mathrm{L}^{-1}\right)$ & 194.5 & 54.1 & $<0.0001$ \\
\hline Erythrocyte sedimentation rate $\left(\mathrm{mm} \mathrm{h}^{-1}\right)$ & 52.2 & 27.2 & $<0.0001$ \\
\hline Adenosine deaminase $\left(\mathrm{U} \mathrm{L}^{-1}\right)$ & 20.7 & 24.6 & 0.002 \\
\hline$\beta 2$-microglobulin $\left(\mathrm{mg} \mathrm{L}^{-1}\right)$ & 2.15 & 2.3 & 0.09 \\
\hline
\end{tabular}

Table 4: Parameters independently associated with the diagnosis of pneumonia

\begin{tabular}{lccc}
\hline & OR & $\begin{array}{l}95 \% \text { Confidence } \\
\text { interval }\end{array}$ & $\mathrm{P}$ \\
\hline $\begin{array}{l}\text { C-reactive protein } \\
\text { Suggestive auscultatory }\end{array}$ & 1.009 & $1.005-1.013$ & $<0.0001$ \\
findings & $5.3-38.5$ & $<0.0001$ \\
Age & 0.97 & $0.95-0.98$ & 0.0004 \\
Pleuritic pain & 5.91 & $2.42-14.42$ & 0.0001 \\
Percent of eosinophils & 0.56 & $0.37-0.85$ & 0.007 \\
\hline
\end{tabular}

3.2 (higher values indicating pneumonia and lower values indicating OALRTI). For this cut-off level the formula classified correctly the patients with a sensitivity of $87.6 \%$, specificity $89.7 \%$, positive predictive value $84.8 \%$, negative predictive value $91.7 \%$, likelihood ratio+ 8.5 (95\% CI 5.2-14.1), likelihood ratio- 0.1 (95\% CI 0.13-0.24), odds ratio 62 (95\% CI 31-125). The area under the ROC curve of this predictive model was 0.93 (95\% CI $0.89-0.96$, $\mathrm{P}<0.0001)$.

\section{DISCUSSION}

We found that the overall diagnostic performance was better for CRP than for ESR, ADA, $\beta 2-\mathrm{M}$ or any of 


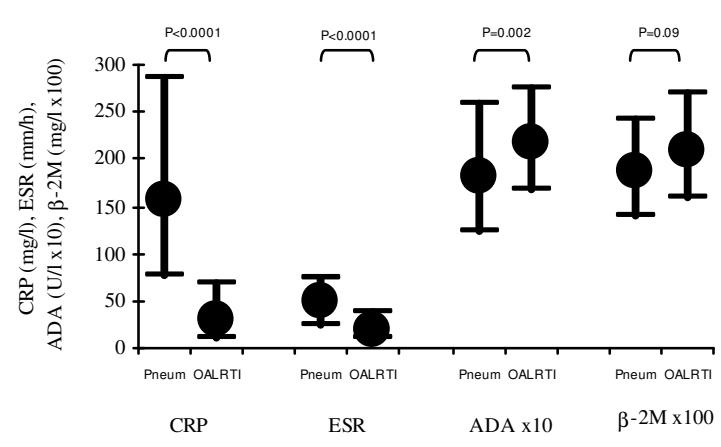

Fig. 1: Median values and interquartile ranges of $\mathrm{C}$ reactive protein (CRP), erythrocyte sedimentation rate (ESR), adenosine deaminase (ADA) and $\beta 2$-microglobulin ( $\beta 2$ $\mathrm{M})$ in patients with pneumonic and nonpneumonic lower respiratory tract infections (OALRTI). For graphical representation the values of ADA have been multiplied by 10 and those of $\beta 2-\mathrm{M}$ multiplied by 100 .

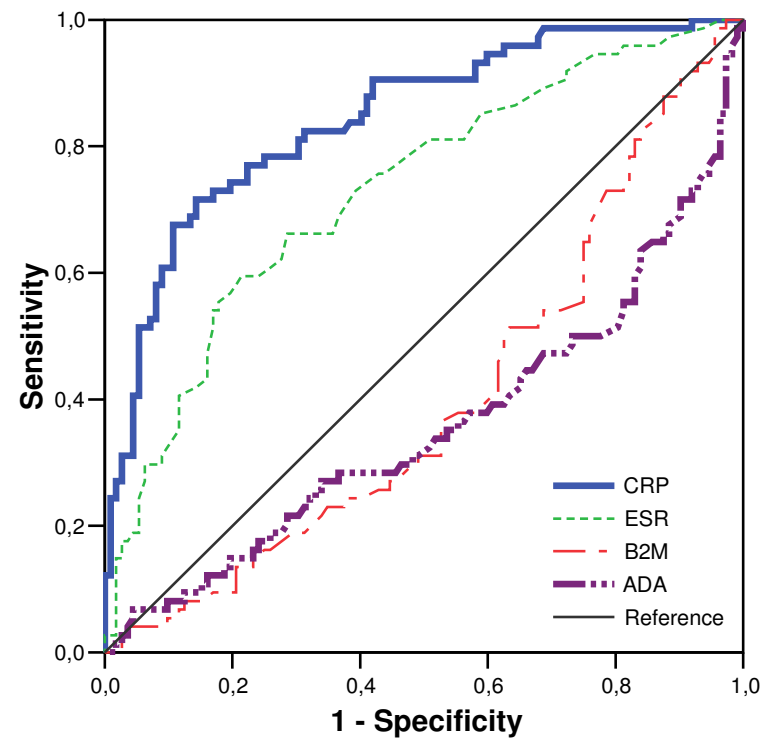

Fig. 2: Receiver operating characteristic curves of Creactive protein (CRP), erythrocyte sedimentation rate (ESR), adenosine deaminase (ADA) and $\beta 2$-microglobulin ( $\beta 2$ $\mathrm{M})$ for the diagnosis of pneumonia

the many demographic, clinical and laboratory parameters studied. To our knowledge no study to date has analyzed the behavior of these acute-phase and immunological markers in the same population of patients, although a few reports have investigated these markers separately.
CRP is a direct and quantitative measure of acutephase reaction with fast kinetics, whereas ESR is an indirect and slower measure of that reaction and is influenced by a number of other factors ${ }^{[30,31]}$. Therefore, CRP is considered superior to ESR on clinical, scientific and practical grounds ${ }^{[32,33]}$. Our findings on patients with lower respiratory tract infections corroborated this point of view, as we found higher and more discriminant responses of CRP than ESR.

A few studies with varied sample sizes have analyzed the CRP levels in patients with pneumonia and OALRTI in children ${ }^{[34,35]}$, in adults ${ }^{[1,36-39]}$ and in the elderly ${ }^{[40]}$, all of which found higher levels of CRP in the former patients. Among the many clinical and laboratory parameters analyzed, we also found CRP to be the variable most tightly related to the diagnosis of pneumonia and the most useful parameter for the differentiation between these two conditions in the univariate, multivariate and ROC curve analyses.

Considering only patients with pneumonia, some authors reported higher CRP levels in pneumococcal pneumonias than in those caused by other organisms ${ }^{\text {[11- }}$ ${ }^{43]}$ as well as an association of CRP with longer hospital stay $^{[42,44]}$. We also found higher levels of CRP associated with longer hospital stay and with pneumococcal etiology, although the differences in the later were not statistically significant (data not shown)

Some studies that evaluated CRP included also ESR in their analysis and concluded that its diagnostic value was lower than that $\mathrm{CRP}^{[1,34-38]}$. We found that ESR was the second more useful parameter, only after CRP, for the differentiation between pneumonia and OALRTI, according to ROC curves, but its accuracy was lower than that CRP and in fact, it was excluded from the multivariate model owing to the higher weight of CRP. In addition to this better performance, the higher sensitivity and quicker and broader changes of CRP as compared with $\operatorname{ESR}^{[32,33,45]}$ and the quickness of its determination ${ }^{[46,47]}$ makes CRP the acute-phase reactant of choice for acute lower respiratory tract infections.

To our knowledge this is the first report comparing ADA in patients with pneumonia and OALRTI. We observed significantly higher values of ADA in patients with OALRTI than in patients with pneumonia, which could be due to the lower leukocyte counts, higher $\beta 2$ $\mathrm{M}$ and higher percentage of lymphocytes observed in the former condition as evidenced by the univariate and multivariate analyses. In addition, increases in this enzyme, which is related to mononuclear cells proliferation and turnover ${ }^{[12,13]}$, would probably need longer periods of cellular immune stimulation and lympho-monocytic cell involvement than that observed 
in typical bacterial pneumonia. Only a few reports have analyzed this enzyme in patients with pneumonia. In such reports patients with atypical pneumonia seemed to have higher ADA levels than patients with bacterial pneumonia and than healthy controls ${ }^{[17-20]}$. Regarding ADA levels in typical bacterial pneumonia, some studies did not find differences with healthy controls ${ }^{[17-}$ ${ }^{19]}$, whereas other authors found higher levels in pneumonic patients ${ }^{[20,21]}$. In this regard, we did not find significant differences between patients with pneumococcal pneumonia and patients with other or unknown etiologies (data not shown). Interestingly, some authors found an independent association of ADA levels with both liver disease and prior use of antibiotics $^{[17]}$. We also found a statistically significant association of ADA with the use of antibiotics and with ALAT serum levels in the univariate and multivariate analyses.

The possible diagnostic value of $\beta 2-\mathrm{M}$ in lower respiratory tract infections has not been addressed in the literature to date, because only a few studies marginally measured $\beta 2-\mathrm{M}$ serum levels in a small number of patients with pneumonia among other diverse entities that did not include OALRTI ${ }^{[26-28]}$. We did not find $\beta 2-$ $M$ to be useful in differentiating pneumonia from OALRTI. In fact, non-significantly higher $\beta 2-\mathrm{M}$ concentrations were observed in patients with the later condition, which, as evidenced in the univariate and multivariate analyses, could be due, among other factors, to the older age, higher concentrations of ADA, lower leukocyte counts and especially, to the higher number of patients with renal failure ( 8 vs. 2 , respectively) in the OALRTI group than in the pneumonia group, a particularly important point considering that $\beta 2-\mathrm{M}$ clearance is renal and that creatinine concentration was, by far, the strongest predictor of $\beta 2-\mathrm{M}$ levels in our series. In addition, $\beta 2-$ $M$ increases in patients with immune activation and both the acute nature of pneumonia and the preferential polymorphonuclear vs. mononuclear response in these patients could also explain these results.

The formula derived from the multivariate analysis could be helpful to primary care physicians for the differential diagnosis of acute lower respiratory tract infections and for the selection of patients who should be referred for radiographic examination and/or derived to hospitals, especially taking into account that OALRTI is much more common than pneumonia ${ }^{[1]}$. Under certain circumstances higher sensitivity or specificity may be desired, which may be easily accomplished by decreasing or increasing, respectively, the cut-off level of the formula. Finally, it should be noted that our patients with OALTRI had a clinical picture of enough severity to attend the emergency ward of a hospital, a fact that reinforces the value of our findings as these patients constitutes the group in which the exclusion of pneumonia is most difficult in the absence of radiographic studies.

However, it should be underscored that the proposed prediction rule was derived from our study population and it needs to be confirmed and validated by other studies from other settings. Nevertheless, at least a certain discriminant value of CRP seems to be consistent across different prevalences of pneumonia, spectrum of ages and geographic settings and populations $^{[1,34-40]}$ and consequently, CRP measurement may constitute a useful adjunct for the differentiation of pneumonia from OALRTI. In addition, the availability of rapid, reliable, cost-effective, near-patient tests for $\mathrm{CRP}^{[46,47]}$ supports the routine use of this determination by general practitioners and emergency ward doctors. A more accurate diagnosis of lower respiratory tract infections in primary care settings would expectedly result in a more rational use of health resources, reduced prescription of antibiotics, economic savings and advantages for the patients.

We conclude that, among the many parameters studied, CRP is the most valuable tool for the differentiation of pneumonia from OALRTI. This measurement, in association with other easily obtained parameters, quite accurately discriminate between these two conditions, which could contribute to improve the diagnostic ability in settings where radiographic studies are not easily available, to select patients who should undergo chest radiographs if they are accessible and to optimize health resources.

\section{REFERENCES}

1. Hopstaken, R.M., J.W. Muris, J.A. Knottnerus, A.D. Kester, P.E. Rinkens and G.J. Dinant, 2003. Contributions of symptoms, signs, erythrocyte sedimentation rate and $\mathrm{C}$-reactive protein to a diagnosis of pneumonia in acute lower respiratory tract infection. Br. J. Gen. Pract., 53: 358-364.

2. Melbye, H., 2002. Community pneumonia - more help is needed to diagnose and assess severity. Br. J. Gen. Pract., 52: 886-888.

3. Hoare, Z. and W.S. Lim, 2006. Pneumonia: update on diagnosis and management. Br. Med. J., 332:1077-1079.

4. Metlay, J.P., W.N. Kapoor and M.J. Fine, 1997. Does this patient have community-acquired pneumonia? Diagnosing pneumonia by history and physical examination. JAMA, 278: 1440-1445. 
5. Metlay, J.P. and M.J. Fine, 2003. Testing strategies in the initial management of patients with community-acquired pneumonia. Ann. Intern. Med., 138: 109-118.

6. Johnson, H.L., C.C. Chiou and C.T. Cho, 1999. Applications of acute phase reactants in infectious diseases. J. Microbiol. Immunol. Infect., 32: 73-82.

7. Gould, J.M. and J.N. Weiser, 2001. Expression of C-reactive protein in the human respiratory tract. Infect. Immun., 69: 1747-1754.

8. Tan, S.S., P.M. Ng, B. Ho and J.L. Ding, 2005. The antimicrobial properties of C-reactive protein (CRP). J. Endotoxin. Res., 11: 249-256.

9. Holmberg, H., L. Bodin, I. Jonsson and A. Krook, 1990. Rapid aetiological diagnosis of pneumonia based on routine laboratory features. Scand. J. Infect. Dis., 22: 537-545.

10. Macfarlane J., W. Holmes and P. Gard et al, 2001. Prospective study of the incidence, aetiology and outcome of adult lower respiratory tract illness in the community. Thorax, 56: 109-114.

11. Shvartzman, P., D. Lieberman and H. Tandeter et al., 2004. Clinical and laboratory profile of febrile respiratory infections in general practice. J. Am. Board Fam. Pract., 17: 32-37.

12. Shvartzman, P., D. Lieberman and H. Tandeter et $a l, 1990$. Serum and pleural adenosine deaminase. Correlation with lymphocytic populations. Chest, 97: 605-610.

13. Ungerer, J.P.J., H.M. Oosthuizen, S.H. Bissbort and W.J. Vermaak, 1992. Serum adenosine deaminase: isoenzymes and diagnostic application. Clin. Chem., 38: 1322-1326.

14. Pushpakom, R., S. Ong-Ajyooth and S Bovornkitti, 1990. The association of adenosine deaminase activity with T-lymphocytes and subsets in pulmonary tuberculosis and bronchogenic carcinoma. J. Med. Assoc. Thai., 73: 244-248.

15. Ida, T., S. Taniai and M. Nitta et al., 1990. Serum adenosine deaminase (ADA) activity in patients with active pulmonary tuberculosis. Kekkaku, 65: 477-481.

16. Collazos, J., P. España, J. Mayo, E. Martínez and F. Izquierdo, 1998. Sequential evaluation of serum adenosine deaminase in patients treated for tuberculosis. Chest,114: 432-435.

17. Fernández Álvarez, R., L. Molinos Martín, J.A. Gullón Blanco, G. Rubinos Cuadrado, A. Jiménez and J. Martínez González-Rio, 2002. Neumonía adquirida en la comunidad: adenosindesaminasa plasmática como marcador etiológico. Med. Clin. (Barc), 119: 481-484.
18. Molinos, L., R. Fernandez, M.J. Dominguez, C. Riesgo, C. Escudero and J. Martinez, 1997. Adenosine deaminase activity in the aetiological diagnosis of community-acquired pneumonia. Scand. J. Infect. Dis., 29: 287-290.

19. Suga, M., M. Ando, H. Nishikawa and S. Araki, 1991. Adenosine deaminase activity and free IL-2 receptor levels in serum from patients with mycoplasma pneumonia. Jpn. J. Med., 30: 108112.

20. Klockars, M., M. Kleemola, M. Leinonen and M. Koskela, 1991. Serum adenosine deaminase in viral and bacterial pneumonia. Chest, 99: 623-626.

21. Hatzistilianou, M., S. Hitoglou and D. Gougoustamou et al., 2002. Serum procalcitonin, adenosine deaminase and its isoenzymes in the aetiological diagnosis of pneumonia in children. Int. J. Immunopathol. Pharmacol., 15: 119-127.

22. Turner, B.J., F.M. Hecht and R.B. Ismail, 1994. $\mathrm{CD}^{+}$T-lymphocyte measures in the treatment of individuals infected with human immunodeficiency virus type 1. A review for clinical practitioners. Arch. Intern. Med., 154: 1561-573.

23. Gazapo, E., R.M. Gazapo and A. Caturla, 1996. Utilidad clínica de la determinación de beta-2microglobulina. Med. Clin. (Barc), 106: 751-755.

24. Kennedy, N., F.M. Whitelaw and J Gutmann et al, 1995. Clinical features and serum $\beta_{2}$-microglobulin levels in HIV-1 positive and negative Tanzanian patients with tuberculosis. Int. J. STD AIDS, 6: 278-283.

25. Collazos, J., Martínez E. and J. Mayo, 1999. Evolution of serum $\beta 2$-microglobulin concentrations during treatment of tuberculosis patients. Scand. J. Infect. Dis., 31: 265-267.

26. Söderblom, T., P. Nyberg, T. Pettersson, M. Klockars and H. Riska, 1996. Pleural fluid beta-2microglobulin and angiotensin-converting enzyme concentrations in rheumatoid arthritis and tuberculosis. Respiration, 63: 272-276.

27. Carstens, J. and P.L. Andersen, 1994. Changes in serum neopterin and serum beta-2-microglobulin in subjects with lung infections. Eur. Respir. J., 7: 1233-1238.

28. Riska, H., T. Pettersson, B. Fröseth and M.

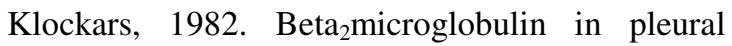
effusions. Acta Med. Scand., 211: 45-50.

29. British Thoracic Society Standards of Care Committee, 2001. BTS Guidelines for the Management of Community Acquired Pneumonia in Adults. Thorax, 56 (Suppl. 4): IV1-64. 
30. van Leeuwen, M.A. and M.H. van Rijswijk, 1994. Acute phase proteins in the monitoring of inflammatory disorders. Baillieres Clin. Rheumatol., 8: 531-552.

31. Gambino, R, 1997. C-reactive protein undervalued, underutilized. Clin. Chem., 43: 20172018.

32. Deodhar, S.D, 1989. C-reactive protein: the best laboratory indicator available for monitoring disease activity. Cleve Clin. J. Med., 56: 126-30.

33. Kenny, R.A., A.P. Saunders and A. Coll et al, 1985. A comparison of the erythrocyte sedimentation rate and serum C-reactive protein concentration in elderly patients. Age Ageing, 14: 15-20.

34. Saijo, M., T. Ishii, M. Kokubo, K. Murono, M. Takimoto and K. Fujita, 1996. White blood cell count, C-reactive protein and erythrocyte sedimentation rate in respiratory syncytial virus infection of the lower respiratory tract. Acta Paediatr. Jpn., 38: 596-600.

35. Babu, G., N.K. Ganguly, S. Singhi and B.N.S. Walia, 1989. Value of C-reactive protein concentration in diagnosis and management of acute lower respiratory infections. Trop. Geogr. Med., 41: 309-315.

36. Castro-Guardiola, A., A. Armengou-Arxe, A. Viejo-Rodriguez, G. Penarroja-Matutano and F. Garcia-Bragado, 2000. Differential diagnosis between community-acquired pneumonia and nonpneumonia diseases of the chest in the emergency ward. Eur. J. Intern. Med., 11: 334-339.

37. Melbye, H., B. Straume and J. Brox, 1992. Laboratory tests for pneumonia in general practice: the diagnostic values depend on the duration of illness. Scand. J. Prim. Health Care, 10: 234-240.

38. Melbye, H. and B. Straume, 1993. The spectrum of patients strongly influences the usefulness of diagnostic tests for pneumonia. Scand. J. Prim. Health Care, 11: 241-246.
39. Smith, R.P. and B.J. Lipworth, 1995. C-reactive protein in simple community-acquired pneumonia. Chest, 107: 1028-1031.

40. Albazzaz, M.K., C. Pal, P. Berman and D.J. Shale, 1994. Inflammatory markers of lower respiratory tract infection in elderly people. Age Ageing, 23: 299-302.

41. Albazzaz, M.K., C. Pal, P. Berman, D.J. Shale, 2004. Contribution to C-reactive protein to the diagnosis and assessment of severity of community acquired pneumonia. Chest, 125:1335-1342

42. Hedlund, J, 1995. Community-acquired pneumonia requiring hospitalisation. Factors of importance for the short- and long-term prognosis. Scand. J. Infect. Dis. Suppl., 97: 1-60.

43. Lehtomaki, K., M. Leinonen, A. Takala, T. Hovi, E. Herva and M. Koskela, 1988. Etiological diagnosis of pneumonia in military conscripts by combined use of bacterial culture and serological methods. Eur. J. Clin. Microbiol. Infect. Dis., 7: 348-354.

44. Ortqvist, A., J. Hedlund, B. Wretlind, A. Carlstrom and M. Kalin, 1995. Diagnostic and prognostic value of interleukin-6 and C-reactive protein in community-acquired pneumonia. Scand. J. Infect. Dis., 27: 457-462.

45. Silvani, A., L. Cirasino, S. Del Guerra, M.V. Lavorato and S. Ragaini, 1995. Modification of phlogosis indices in pneumonia during antibiotic therapy. Recenti. Prog. Med., 86: 63-67.

46. Flanders, S.A., J. Stein and G. Shochat et al., 2004. Performance of a bedside C-reactive protein test in the diagnosis of community-acquired pneumonia in adults with acute cough. Am. J. Med., 116: 529535.

47. Dahler-Eriksen, B.S., J.F. Lassen, P.H. Petersen, E.D. Lund, T. Lauritzen and I. Brandslund, 1997. Evaluation of a near-patient test for C-reactive protein used in daily routine in primary healthcare by use of difference plots. Clin. Chem., 43: 20642075. 